\title{
Surface Roughness of Solidified Mold Flux in Continuous Casting Process
}

\author{
Koichi TSUTSUMI, Tetsuya NAGASAKA ${ }^{1)}$ and Mitsutaka HINO ${ }^{1)}$
}

Formerly at Graduate School of Engineering, Tohoku University, now at Materials \& Processing Research Center, NKK Corporation, 1, Kokan-cho, Fukuyama, Hiroshima-prf., 721-8510 Japan. 1) Graduate School of Engineering, Tohoku University, Aoba-yama 02, Sendai, 980-8579 Japan.

(Received on March 3, 1999; accepted in final form on July 26, 1999)

\begin{abstract}
Heat transfer in continuous casting mold is important to decide the surface quality of the cast slab of middle carbon steel. Many researchers have recently studied the mechanism of reducing the heat transfer between the mold and the solidified shell, and some of them have pointed out that the interfacial thermal resistance between the mold and surface of solidified mold flux has caused decreasing heat transfer.

In the present study, the surface roughness of solidified mold fluxes used for low carbon and middle carbon steel casting, $\mathrm{Na}_{2} \mathrm{O}-\mathrm{CaO}-\mathrm{SiO}_{2}$ and $\mathrm{Li}_{2} \mathrm{O}-\mathrm{CaO}-\mathrm{SiO}_{2}$ slag systems, was measured by a confocal scanning laser microscope combined with an infrared image furnace. It was found that the surface roughness was in the range of approximately $10-30 \mu \mathrm{m}$ when the crystalline phase precipitated. Furthermore, the faster the cooling rate, the smoother the surface roughness of the solidified mold flux became. In the contrast, the surface roughness of the slag, of which critical cooling rate is faster, increased. The surface roughness of the mold flux for middle carbon steel casting became rougher than that for low carbon steel casting. As a result, the surface roughness was related to normalized cooling rate, which is the ratio of actual experimental cooling rate to critical cooling rate. The experimental data of surface roughness were fairly in agreement with calculated values on the assumption of one dimensional heat transfer in the continuous casting mold.
\end{abstract}

KEY WORDS: continuous casting; mold flux; critical cooling rate; surface roughness; confocal scanning laser microscope.

\section{Introduction}

Formation of surface crack in steel slab is one of the most serious problems in the continuous casting process of middle carbon steel. It is well known that the relatively slow cooling of the slab in the mold is effective in preventing the surface crack formation. ${ }^{1)}$ The heat transfer from liquid steel to copper mold through the solidified steel shell and mold flux layer should be suppressed in order to achieve such slow cooling rate. For this purpose, methodology has been discussed by many researchers based on experimental results in laboratories ${ }^{2,3)}$ and heat transfer calculations. ${ }^{4)}$ It is found from these fundamental investigations that the mold flux plays a very important role on the heat transfer from steel to copper mold. The effects of physical properties of mold flux such as viscosity, liquidus temperature, crystallization temperature and thermal diffusivity $^{5)}$ on the cooling rate of steel slab have also been discussed. Among such physical properties, glasscrystal transformation behavior of the mold flux which can occur during cooling is found to be one of the most important factors to control heat transfer in the mold. That is, some amount of crystalline phase could precipitate in the solidified glassy mold flux, and such crystalline phase would suppress the heat transfer through the mold flux layer. However, when the thermal conductivity in the solidified mold flux was measured by the various experimental methods, thermal conductivity of the crystalline phase was larger than that of the glassy phase. ${ }^{6}$ This experimental result was inconsistent with the experience in a continuous casting operation. There are numerous opinions concerning the mechanism of decreasing heat transfer between the mold and solidified shell, but the mechanism has not been made clear. Three opinions have been mainly proposed. One is that increasing pores in the mold flux film cause the thermal resistance between the mold and solidified shell. This is proposed by Kumakura et al. ${ }^{7)}$ and Chikano et $a l^{8)}$ Another opinion is that the radiative heat flux decreases in the crystalline phase. Yamauchi et al. ${ }^{3)}$ reported that the ratio of radiative heat flux was approximately $20 \%$ of the total heat flux. Kawamoto et al. ${ }^{9)}$ reported that the ratio of radiative heat flux was $27 \%$ in the liquid mold flux film and $6 \%$ in the solid mold flux film of the total heat flux. The third opinion is that the interfacial thermal resistance causes the decreasing heat transfer. Namely, some researchers ${ }^{3,6,10-13)}$ have pointed out that there might be a possibility of the increase of interfacial thermal resistance between the mold and mold flux due to the crystalline phase precipitation in the solidified mold flux. On the other 


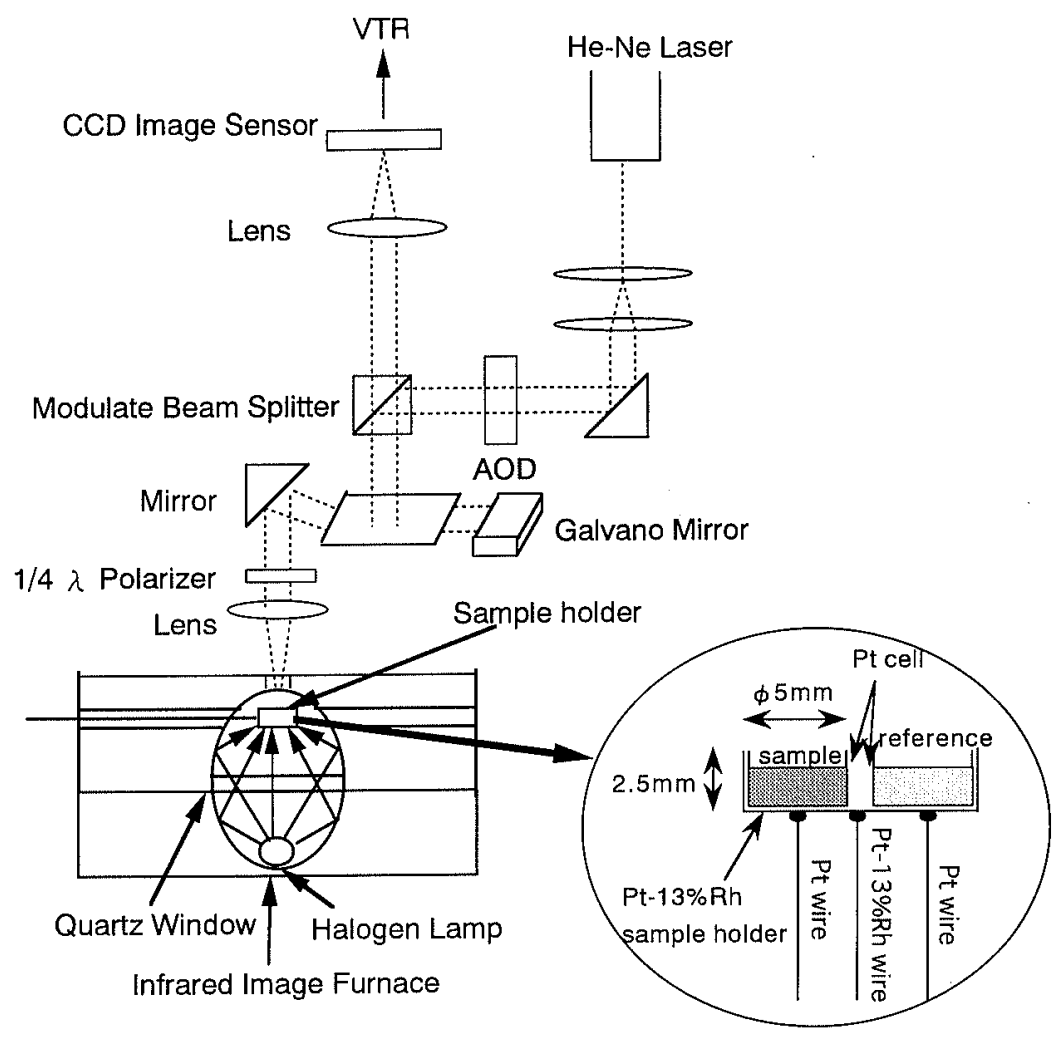

Fig. 1. Schematic diagram of confocal laser scanning microscope with infrared image furnace.

hand, a rough surface of the solidified mold flux and air gap between the mold and solidified mold flux have been observed in the practical continuous casting process. Such a rough surface would be due to the precipitation of crystalline phase and result in the suppression of heat transfer while precise heat transfer mechanism in the continuous casting mold is still unknown. There are a few quantitative experimental data $^{6)}$ on the surface roughness of the solidified mold flux.

The objective of the present work is to measure the surface roughness of the solidified industrial mold fluxes and several alkaline metal oxide containing monocalcium-silicate slags by a confocal scanning laser microscope combined with an infrared image furnace and to provide fundamental information on the mechanism of decreasing the heat transfer from steel to copper mold through the mold flux. The relation between surface roughness and cooling rate was discussed by means of the critical cooling rate of glass-crystal transformation of mold flux which was investigated by the present authors. ${ }^{14)}$ Finally, the surface roughness was estimated from the reported data in the practical continuous casting machine by assuming one dimensional heat transfer in the mold, and the calculated surface roughness was compared with the observed.

\section{Experimental}

Figure 1 shows the schematic diagram of the confocal scanning laser microscope combined with an infrared image furnace (Laser Tech Co. Ltd., special ordered). This equipment was used for the observation of the crystalline phase precipitation and the measurement of the surface roughness of solidified mold flux. The specimen was heated or cooled by the radiation of a halogen lamp with a maximum heating rate of $10 \mathrm{~K} / \mathrm{s}$ and a cooling rate of $33 \mathrm{~K} / \mathrm{s}$. The detail assembly of the sample holder in the furnace is also illustrated in Fig. 1. Two crucibles were set in a platinum holder. One was for a sample and the other was for a reference material such as $\mathrm{Al}_{2} \mathrm{O}_{3}$. Two sets of $\mathrm{R}$-type thermocouples (Pt-13mass \% Rh/Pt) were attached to the sample holder to measure the crystallization temperature by detecting exothermic the peak with differential thermal analysis (DTA) technique. In a continuous casting machine, the molten mold flux is flowed into the aperture between the mold and solidified shell and is quenched by a water-cooled copper mold. Strictly speaking, this cooling method by an infrared image furnace is different from the cooling method by a water-cooled copper plate. The cooling rate on the surface of the solidified shell is unknown because it is difficult to measure the temperature of the mold surface and solidified mold flux. Formerly present authors estimated the cooling rate between the mold and solidified shell to be 10 to $100 \mathrm{~K} / \mathrm{s.}^{14}$ ) Sugitani et al. ${ }^{15)}$ estimated the cooling rate on the surface of solidified shell to be about $20 \mathrm{~K} / \mathrm{s}$. On the other hand the cooling rate by using infrared image furnace can be controlled from $0.015-33 \mathrm{~K} / \mathrm{s}$. Therefore, the cooling rate using an infrared image furnace can cover the actual cooling rate in the mold of the continuous casting process. That is, present study's method could reasonably simulate the cooling behavior between the mold and solidified shell in a continuous casting process.

The industrial mold flux or alkaline metal oxide containing mono-calcium-silicate slags was premelted 


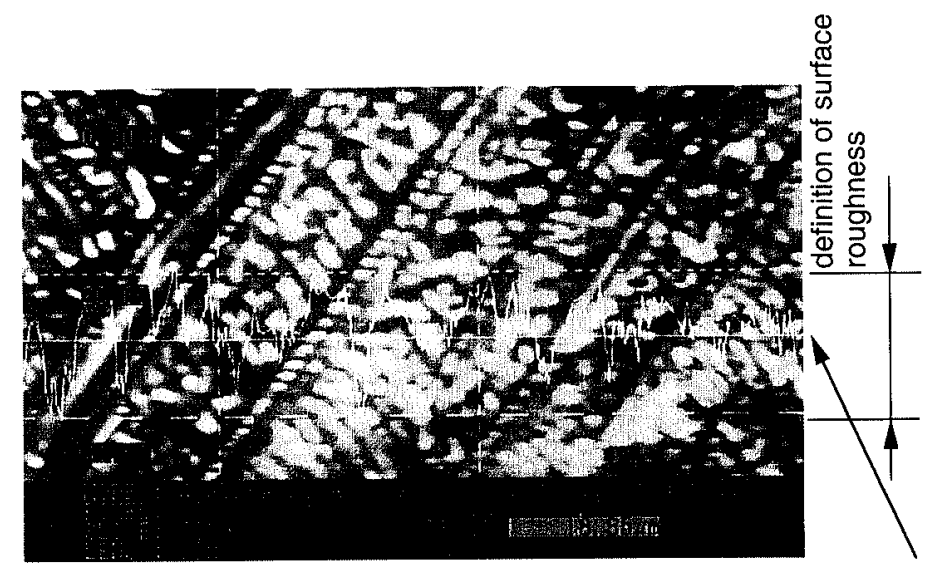

scanned line

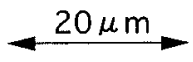

Fig. 2. An example picture of measuring the surface roughness of mold flux, "LC", for low carbon steel casting at cooling rate of $5.0 \mathrm{~K} / \mathrm{s}$.

in a platinum crucible in an inert gas atmosphere and quenched to obtain a homogenous specimen. This specimen was then set in the microscope equipment and heated to the aimed temperature which was just $100 \mathrm{~K}$ above each liquidus temperature. After the specimen was kept at this temperature for $1 \mathrm{~min}$, it was cooled to room temperature at the programmed rate $(0.015-$ $30 \mathrm{~K} / \mathrm{s}$ ) under an purified Ar flow and then was supplied for the surface roughness measurement. Sample weight was $50 \mathrm{mg}$.

The surface roughness was determined using a computer aided surface depth profile measurement system which was equipped with the confocal scanning laser microscope. When the surface roughness was measured, the high magnification lens of which the numerical aperture was high had to be selected in order to measure the correct surface roughness. As a result, the magnitude of the observed area was $\times 3500$ magnitude in our equipment. So three observed area were selected at random for measuring the surface roughness in each sample. The digital surface image data were captured and stored in a computer. Figure $\mathbf{2}$ is a typical example of depth profile measurement. The surface image was automatically focused at each point on the scanned line by analyzing the intensity of the laser beam reflected from the surface. The surface depth profile is shown by fine white lines in Fig. 2. Five lines were scanned in each observed area, so that fifteen lines were totally selected for measuring the surface roughness of each specimen. Difference between the minimum and the maximum height was recorded as surface depth profile of each scanned line. The surface roughness was defined as the average of the fifteen values. Deeper pits were rarely observed during the scanning of the surface. Since the these pits was usually too deep and beyond the detection limit of the laser beam reflection, such pits were not taken into account for the evaluation of surface roughness in the present work.

The surface roughness measurement was made for several industrial mold fluxes and alkaline metal oxide
Table 1. Chemical composition (in mass\%) and physical properties of mold fluxes

\begin{tabular}{|c|c|c|c|}
\hline & LC & MC1 & MC2 \\
\hline $\mathrm{SiO}_{2}$ & 34.6 & 31.1 & 31.6 \\
\hline $\mathrm{Al}_{2} \mathrm{O}_{3}$ & 6.4 & 3.3 & 3.6 \\
\hline $\mathrm{CaO}$ & 33.9 & 46.1 & 45.1 \\
\hline $\mathrm{F}$ & 8.4 & 9.4 & 9.9 \\
\hline $\mathrm{Na}_{2} \mathrm{O}$ & 11.2 & 7.7 & 7.3 \\
\hline $\mathrm{Li}_{2} \mathrm{O}$ & 4.5 & 3.0 & 3.8 \\
\hline $\mathrm{MgO}$ & 2.2 & 0.3 & 1.8 \\
\hline $\mathrm{CaO} / \mathrm{SiO}_{2}$ & 0.98 & 1.48 & 1.43 \\
\hline Viscosity(Pa.s $)^{(0)}$ & 0.09 & 0.05 & 0.05 \\
\hline Crystallization temp.(K) & 1303 & 1418 & 1402 \\
\hline
\end{tabular}

$\left({ }^{\star}\right)$ The viscosity was measured by the Falling Ball Method.

$\left.{ }^{\star \star}\right)$ Crystallization temperature was measured by the DTA

analysis at the cooling rate of $10 \mathrm{~K} / \mathrm{min}$ from $1573 \mathrm{~K}$

containing mono-calcium-silicate slags. Table 1 shows the chemical composition and some physical properties of industrial mold fluxes used in the present work. These fluxes are used in Japanese steelmaking companies for high speed casting of low carbon and middle carbon steel casting. These fluxes were premelted in a platinum crucible in air before supplying the experiment. The chemical composition of these mold fluxes shown in Table 1 are analyzed values after premelting. It is generally believed that mold flux with high crystallization temperature is easy to precipitate crystalline phase and is effective in decreasing the heat transfer between the mold and solidified shell. ${ }^{12}$ Crystallization temperature of mold flux for middle carbon steel casting would be, therefore, higher than that of mold flux for low carbon steel casting. $\mathrm{Na}{ }_{2} \mathrm{O}-\mathrm{CaO}-\mathrm{SiO}_{2}$ and $\mathrm{Li}_{2} \mathrm{O}-$ $\mathrm{CaO}-\mathrm{SiO}_{2}$ ternary slags were used as the simulated mold fluxes. Since the critical cooling rates for the crystallization of $\mathrm{Na}_{2} \mathrm{O}-\mathrm{CaO}-\mathrm{SiO}_{2}$ and $\mathrm{Li}_{2} \mathrm{O}-\mathrm{CaO}-\mathrm{SiO}_{2}$ slags were measured in our previous work, ${ }^{14}$ ) such information can be applied to discuss the relation between critical cooling rate and surface roughness of these slags. The samples of alkaline metal oxide containing monocalcium-silicate slag were prepared from reagent grade 
Table 2. Composition and critical cooling rates of $\mathrm{Na}_{2} \mathrm{O}-$ $\mathrm{CaO}-\mathrm{SiO}_{2}$ and $\mathrm{Li}_{2} \mathrm{O}-\mathrm{CaO}-\mathrm{SiO}_{2}$ slags.

\begin{tabular}{|c|r|r|r|r|r|r|r|r|}
\hline & NCS1 & NCS2 & NCS3 & NCS4 & LCS1 & LCS2 & LCS3 & LCS4 \\
\hline $\mathrm{SiO}_{2}$ (mass\%) & 48.6 & 46.8 & 43.2 & 41.1 & 48.9 & 47.6 & 43.9 & 41.2 \\
\hline $\mathrm{CaO}$ (mass\%) & 44.8 & 42.9 & 40.8 & 39.0 & 46.9 & 45.4 & 42.3 & 39.1 \\
\hline $\mathrm{Na}_{2} \mathrm{O}$ (mass\%) & 6.6 & 10.3 & 16.0 & 19.9 & 0 & 0 & 0 & 0 \\
\hline $\mathrm{Li}_{2} \mathrm{O}$ (mass\%) & 0 & 0 & 0 & 0 & 4.2 & 7 & 13.8 & 19.7 \\
\hline $\mathrm{CaO} / \mathrm{SiO}_{2}$ (mass ratio) & 0.92 & 0.92 & 0.95 & 0.95 & 0.96 & 0.95 & 0.96 & 0.95 \\
\hline
\end{tabular}

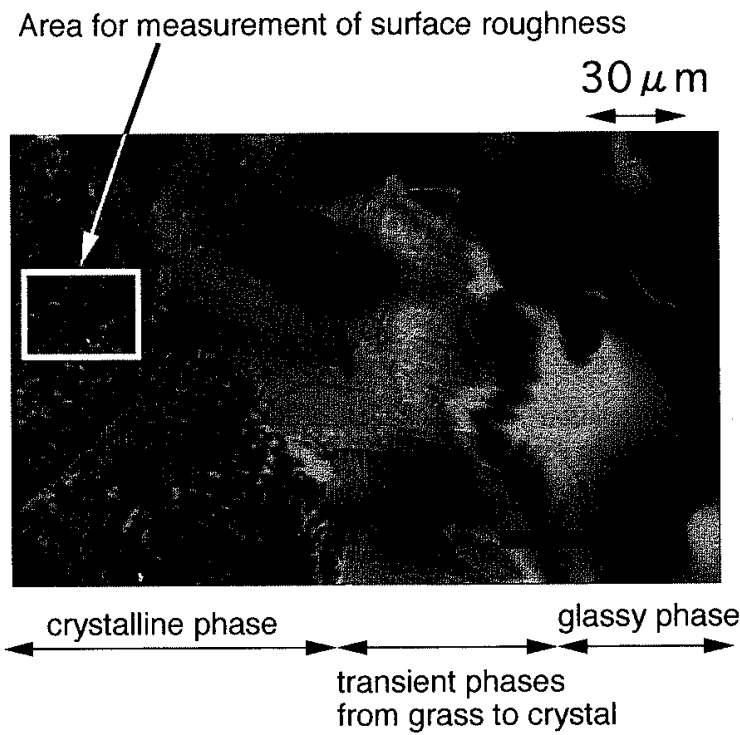

Fig. 3. An example photo of solidified surface of mold flux, "LC", at cooling rate of $3.33 \mathrm{~K} / \mathrm{s}$.

of chemicals such as $\mathrm{CaCO}_{3}, \mathrm{SiO}_{2}, \mathrm{Na}_{2} \mathrm{CO}_{3}$ and $\mathrm{Li}_{2} \mathrm{CO}_{3}$. These powder materials were well mixed at the desired composition and premelted in a platinum crucible in air at the aimed temperature which was $100 \mathrm{~K}$ higher than the each liquidus temperature and quenched with helium stream. The premelted slag samples were crushed, analyzed and supplied for the experimental runs. Chemical composition of these slags used in the present work are listed in Table $2 . \mathrm{CaO} / \mathrm{SiO}_{2}$ ratio in all slags were adjusted to unity ( mono-calcium-silicate ).

\section{Results}

\subsection{Morphology of Mold Flux after Solidification}

Figure 3 shows a photo of the solidified surface of mold flux , "LC", for low carbon steel casting at the cooling rate of $3.33 \mathrm{~K} / \mathrm{s}$ to the room temperature as a typical example. Generally the reflectance of mold flux is smaller than that of metal, so that it is difficult to observe a bright picture clearly by the confocal scanning laser microscope. ${ }^{16)}$ The area presented in Fig. 3 can be divided into three regions. The right area is the glassy phase and the left area is the crystalline phase. The center area of this photo is transient area from glass to crystal. It can be seen from this photo that the surface of crystalline area is rougher than that of the glassy area.

\subsection{Surface Roughness of Alkaline Metal Oxide Con- taining Mono-calcium-silicate Slags}

In order to make quantitative discussions on the relation between surface roughness and cooling rate, the surface roughness measurement by same technique was

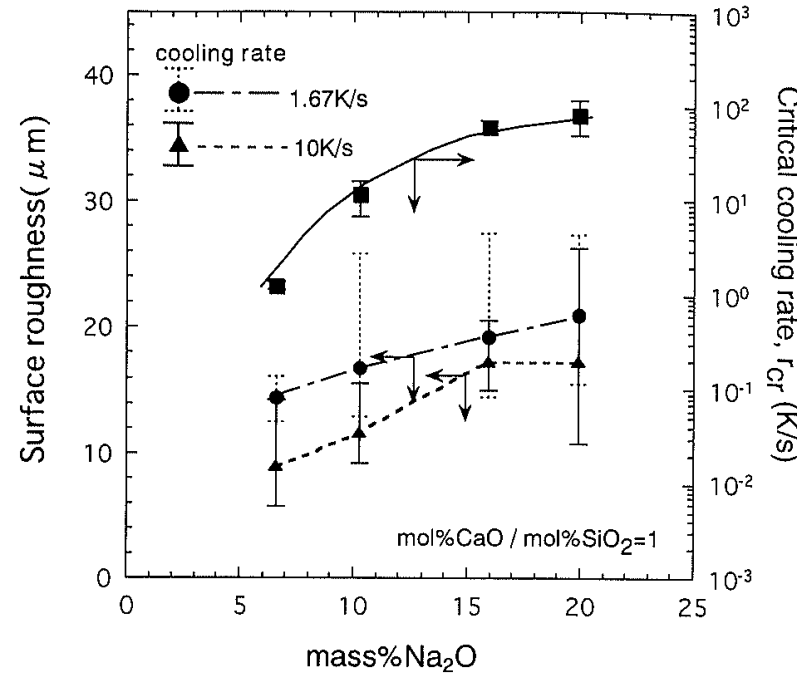

Fig. 4. Variation of surface roughness and critical cooling rate, $r_{\text {cr }}$, with mass $\% \mathrm{Na}_{2} \mathrm{O}$ in $\mathrm{Na}_{2} \mathrm{O}-\mathrm{CaO}-\mathrm{SiO}_{2}$ system.

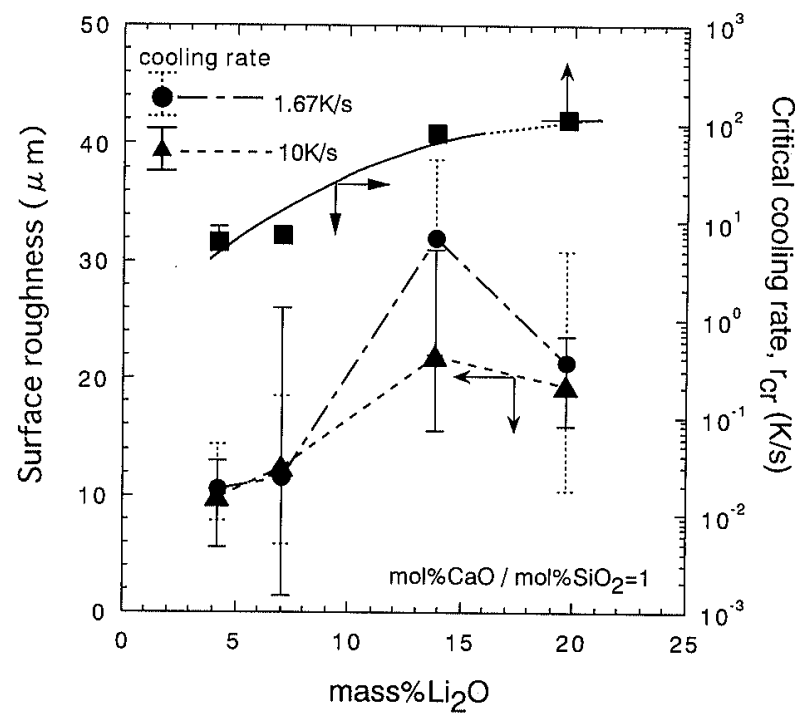

Fig. 5. Variation of surface roughness and critical cooling rate, $r_{c r}$, with mass $\% \mathrm{Li}_{2} \mathrm{O}$ in $\mathrm{Li}_{2} \mathrm{O}-\mathrm{CaO}-\mathrm{SiO}_{2}$ system.

conducted for some alkaline metal oxide containing mono-calcium-silicate slags, of which critical cooling rates were known by the present authors. ${ }^{14)} \mathrm{Na}_{2} \mathrm{O}$ or $\mathrm{Li}_{2} \mathrm{O}$ was added to mono-calcium-silicate. Figures 4 and 5 show the variation of surface roughness with mass $\%$ $\mathrm{Na}_{2} \mathrm{O}$ in $\mathrm{Na}_{2} \mathrm{O}-\mathrm{CaO}-\mathrm{SiO}_{2}$ slag (NCS) and mass $\% \mathrm{Li}_{2} \mathrm{O}$ in $\mathrm{Li}_{2} \mathrm{O}-\mathrm{CaO}-\mathrm{SiO}_{2}$ slag (LCS) observed at two levels of the cooling rate $(1.67$ and $10 \mathrm{~K} / \mathrm{s})$. The critical cooling rates of these slags investigated in the previous work are also presented in both figures for the comparison. Since the critical cooling rates of these slags are in the range from $1.28 \mathrm{~K} / \mathrm{s}\left(6.6 \mathrm{mass} \% \mathrm{Na}_{2} \mathrm{O}\right.$ of NCS) to higher than $110.9 \mathrm{~K} / \mathrm{s}\left(19.7\right.$ mass $\% \mathrm{Li}_{2} \mathrm{O}$ of LCS), most of the specimens cooled at $1.67 \mathrm{~K} / \mathrm{s}$ are completely crystalline and some of the low alkaline oxide containing slags consists of mainly crystalline phase with small amount of glassy phase. The average values of the surface roughness for whole slag samples are plotted in Figs. 4 and 5. Although the observed values of the surface roughness are somewhat scattered, they increases with the addition of $\mathrm{Na}_{2} \mathrm{O}$ or $\mathrm{Li}_{2} \mathrm{O}$ to mono-calcium-silicate 


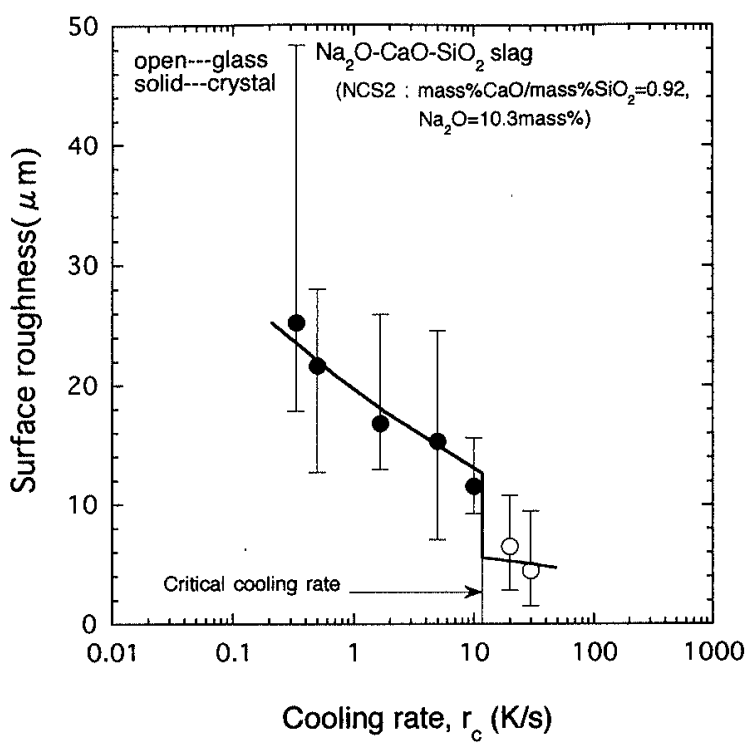

Fig. 6. Relation between cooling rate, $r_{c}$, and surface roughness in $\mathrm{Na}_{2} \mathrm{O}-\mathrm{CaO}-\mathrm{SiO}_{2}$ system.

slag. It is also observed that the surface roughness of both slags becomes larger with slower cooling rate. The critical cooling rates of both slags have been found to be faster with increasing alkaline oxide content in the slag. ${ }^{14)}$ This suggests that higher alkaline oxide content in slag results in larger surface roughness at a constant cooling rate. Such deduction is in good accord with the observed similar dependency of the surface roughness and the critical cooling rate on the slag composition. Figure 6 shows the relation between the surface roughness and cooling rate, $r_{\mathrm{c}}$, for NCS2 in Table 2, where open and closed keys denote surface roughness of glassy and crystalline phases, respectively, and error bars correspond to the scatter of the measured values. The faster the cooling rate is, the smoother the surface roughness becomes. Therefore the surface roughness of NCS2 becomes drastically small when the slag is cooled at a rate higher than the critical cooling rate where the slag is completely glassy.

\subsection{Surface Roughness of Industrial Mold Flux}

The surface roughness of three kinds of industrial mold fluxes after cooling can be classified into three states depending on the cooling rate, $r_{c}$, on the present experimental conditions. "LC" and "MC2" are being used for low carbon steel casting and middle carbon steel casting respectively. They were found to be completely crystalline when the cooling rate was slower than $0.8 \mathrm{~K} / \mathrm{s}$ for $\mathrm{LC}$ and $15 \mathrm{~K} / \mathrm{s}$ for $\mathrm{MC} 2$, and they consisted of glass + crystal mixtures at $r_{\mathrm{c}}=0.8 \mathrm{~K} / \mathrm{s}$ to $6 \mathrm{~K} / \mathrm{s}$ for $\mathrm{LC}$ and $r_{\mathrm{c}}>15 \mathrm{~K} / \mathrm{s}$ for $\mathrm{MC} 2$, while only glassy phase was observed for LC when $r_{\mathrm{c}}$ was greater than $6 \mathrm{~K} / \mathrm{s}$. No glassy phase was observed for another mold flux, "MC1", for middle carbon steel casting even at $r_{\mathrm{c}}=33 \mathrm{~K} / \mathrm{s}$ which was the attainable maximum cooling rate by our infrared image furnace. The results are plotted as a function of the cooling rate in Fig. 7. As seen from this figure, the surface roughness in the crystalline region becomes larger with decreasing the cooling rate for each kind of mold flux whereas that of the glassy region tends to increase

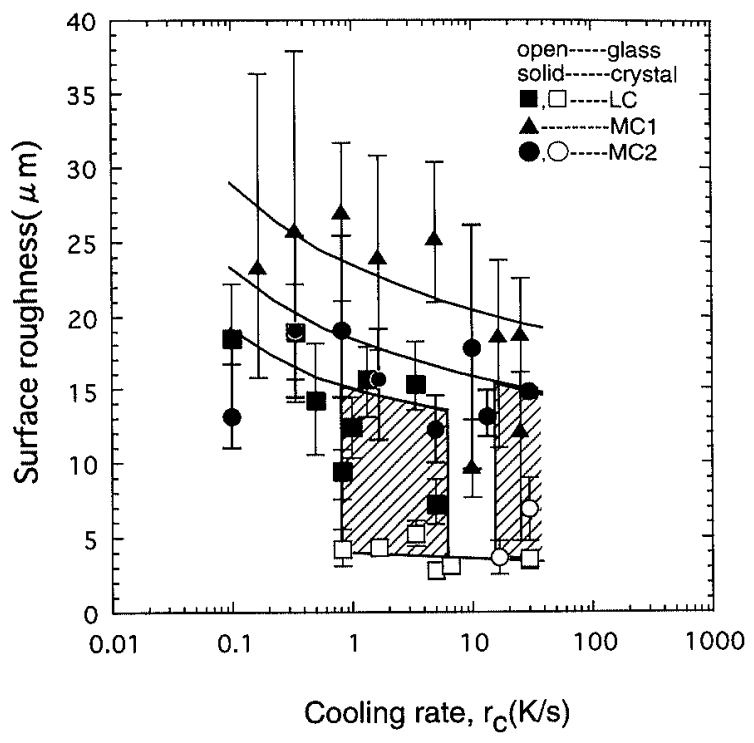

Fig. 7. Relation between cooling rate, $r_{c}$, and surface roughness of solidified mold fiuxes for low and middle carbon steel casting.

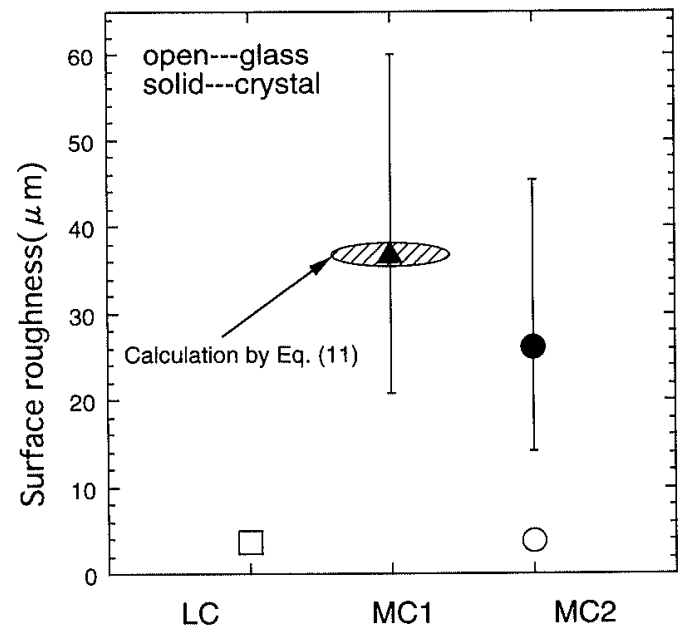

Fig. 8. Surface roughness in the quenching test of mold fluxes on the water-cooled copper plate.

slightly. The surface roughness in the crystalline area in three kinds of mold fluxes is in the range of approximately $10-30 \mu \mathrm{m}$. On the other hand, the surface roughness in the crystalline region is approximately $10 \mu \mathrm{m}$ larger than that in the glassy area for LC and MC2. Such difference of the surface roughness between the crystalline and glassy region results in a large discontinuous change of the surface roughness at around the critical cooling rate. The surface roughness in crystalline region of $\mathrm{MCl}$ is the largest and that of LC is the smallest among three kinds of mold fluxes when the cooling rate is the same.

Another experiment was conducted as follows in order to confirm whether this experimental method could simulate the cooling condition in a continuous casting process. $20 \mathrm{~g}$ of each industrial mold flux was melted in a platinum crucible at $1673 \mathrm{~K}$ with a horizontal type electric resistance furnace and then quenched by pouring it on a water-cooled copper plate. The mold flux surface contacted with copper plate was observed with the laser scanning microscope to measure the surface roughness. The results are shown in Fig. 8. In spite of faster cooling 
rate by this quenching test, no glassy phase is observed for $\mathrm{MC1}$. MC2 contained much more crystalline phase, and LC was found to be completely glassy due to rapid cooling. The trend of the larger surface roughness of MC1 than that of MC2 in crystalline phase was the same as that presented in Fig. 7. In addition, the absolute values of the surface roughness observed by the quenching test is larger than those obtained by the infrared image furnace. The cooling rate in the quenching test using a water-cooled copper plate is estimated to be from 10 to $100 \mathrm{~K} / \mathrm{s}^{14}$ ) which is almost equivalent to that between the mold and the solidified shell in a continuous casting machine. The surface roughness cooled by the infrared image furnace in Fig. 7 are about $20 \mu \mathrm{m}$ of $\mathrm{MC1}$ and $15 \mu \mathrm{m}$ of $\mathrm{MC} 2$ at the cooling rate of $10-100 \mathrm{~K} / \mathrm{s}$, and those quenched by the water-cooled copper plate in Fig. 8 are about $37 \mu \mathrm{m}$ of $\mathrm{MCl}$ and $26 \mu \mathrm{m}$ of MC2. Therefore, it can be concluded that the surface roughness of solidified mold flux cooled by the infrared image furnace is fairly in agreement with the half of surface roughness in the quenching test by a water-cooled copper plate and could nearly simulate the cooling condition in continuous casting.

\subsection{Change of Surface Roughness during Reheating}

Watanabe et $a$ l. $^{12)}$ investigated the surface condition of some industrial mold fluxes during reheating of the quenched fluxes at $1.67 \mathrm{~K} / \mathrm{s}$ from room temperature up to $923 \mathrm{~K}$. As a result, wrinkles appeared and surface roughness became greater during reheating. The depth or height of wrinkle was roughly changed from $3 \mu \mathrm{m}$ to $7 \mu \mathrm{m}$ before and after reheating respectively. There is a possibility of reheating of mold flux in the continuous casting machine when the heat that comes into the flux from the slab is greater than that extracted from the flux to the copper mold. If such reheating occurs, wrinkles should be formed on the surface of the mold flux and such wrinkles, as well as the surface roughness, would affect the heat transfer mechanism between the copper mold and the slab through mold flux. Therefore, change of the surface condition of the industrial mold flux in the reheating process was also studied in the present work in order to confirm Watanabe et al.'s finding quantitatively. Glassy mold fluxes, which were preliminary melted and quenched, were reheated from room temperature at a constant heating rate $(0.33-6.67 \mathrm{~K} / \mathrm{s})$ and kept at the aimed holding temperature for $10 \mathrm{~min}$, and then they were quenched and supplied for surface analysis with the laser scanning microscope. The holding temperature was adjusted at $100 \mathrm{~K}$ higher than each recrystallization temperature which was determined in the present work by detecting the exothermic peak of DTA signal during reheating. LC was selected as a test mold flux because its critical cooling rate was relatively slow and, thus, completely glassy sample could be easily obtained by quenching in the infrared image furnace.

As shown in Fig. 9, crystalline phase appears during the reheating process above the recrystallization temperature and the surface seems to be rough as well as the cooling process shown in Fig. 7. The surface roughness observed during reheating is shown in Fig. 9

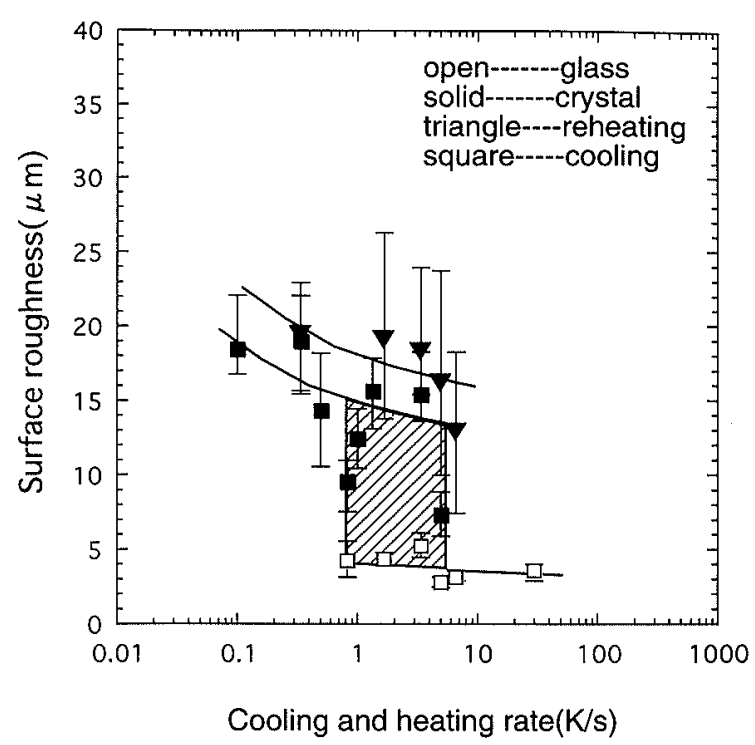

Fig. 9. Comparison surface roughness between by reheating and cooling process. Flux sample is LC.

as a function of heating rate. The results during the cooling process for LC presented in Fig. 7 are also plotted in Fig. 9 for comparison. The surface roughness decreases with increasing reheating rate. The surface roughness in the reheating process is slightly larger than that in the cooling process, but the difference is not siginificant. Such results indicate that the surface condition of mold flux is essentially the same in the reheating and cooling processes and the surface roughness can be estimated from the cooling or reheating rate.

\section{Discussion}

\subsection{Relation between Normalized Cooling Rate and Surface Roughness}

The surface roughness of solidified mold flux is an important factor to control the heat transfer from steel to copper mold through the mold flux layer in the continuous casting machine, and such heat transfer can be suppressed with larger surface roughness. This means that the crystalline precipitation should be promoted if the relatively slow cooling rate is necessary in, for example, middle carbon steel casting process. The degree of crystalline precipitation on the continuous cooling condition depends on not only the actual cooling rate but also the critical cooling rate. That is, the ratio of the actual cooling rate to the critical cooling rate is an important parameter for the prediction of the degree of crystalline precipitation, surface roughness and heat transfer. This ratio is defined as the "normalized cooling rate", $r_{n}$, in this paper, and the solid line for LC shown in Fig. 7 is redrawn in Fig. 10 by using this new parameter. Figure 10 demonstrates the relation between the normalized cooling rate and surface roughness of simulated slags. It is interesting that the surface roughness of crystalline phase can be expressed by a single smooth curve which is independent of the slag system. It is recognized from Fig. 10 that no crystalline phase should precipitate when the normalized cooling rate is greater than unity. Therefore surface roughness should 


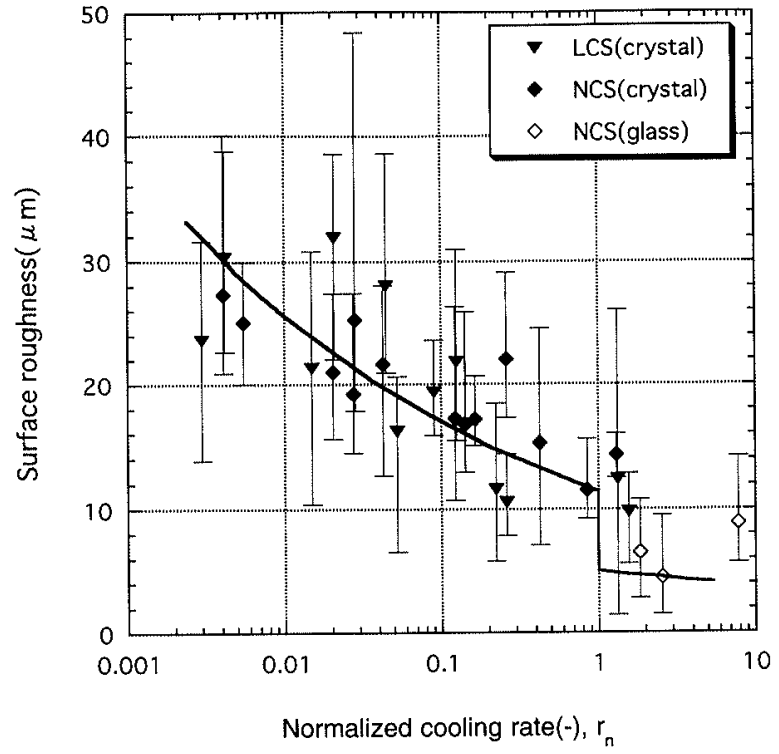

Fig. 10. Relation between normalized cooling rate, $r_{n}$, and surface roughness using simulated slags.

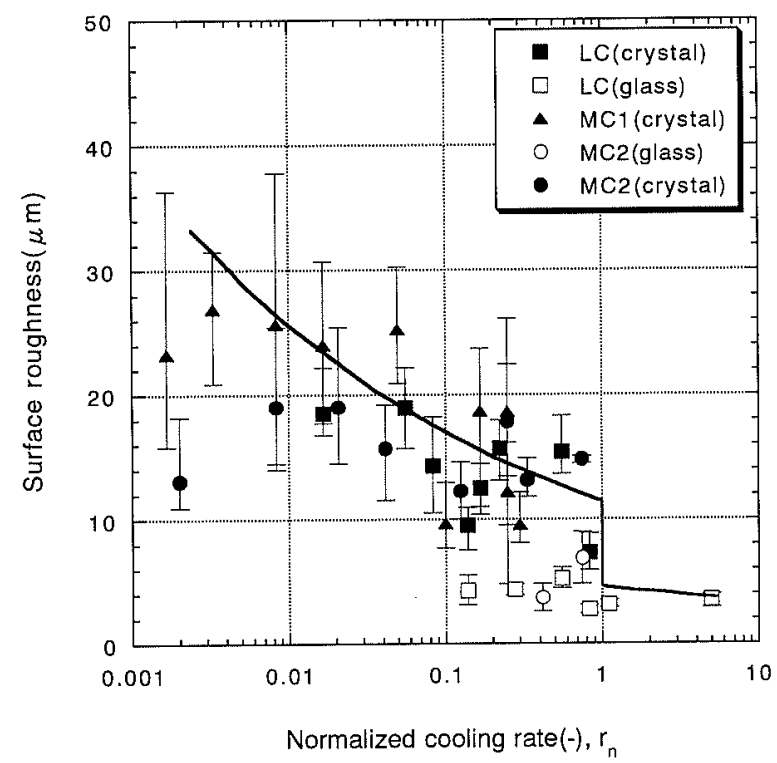

Fig. 11. Relation between normalized cooling rate, $r_{n}$, and surface roughness using industrial mold fluxes.

discontinuously jump up around unit $r_{\mathrm{n}}$ with decreasing $r_{\mathrm{n}}$ from $r_{\mathrm{n}}>1$. The surface roughness increased gradually with further decreasing of the cooling rate. This empirical relation between the surface roughness and the normalized cooling rate is applied to the industrial mold fluxes as shown in Fig. 11. The solid line drawn in this figure is identical to that in Fig. 10. It is seen from Fig. 11 that the results of LC show good agreement with this empirical relation in spite of the large difference of slag composition between LC and simulated slags. Thus, it would be reasonable to assume that this empirical relation would be independent of the slag composition in the present experimental conditions. If this assumption is reasonable, the critical cooling rates of $\mathrm{MC} 1$ and $\mathrm{MC} 2$ can be estimated by fitting their results to this empirical relation. As it was mentioned earlier, the critical cooling rates of $\mathrm{MCl}$ and $\mathrm{MC} 2$ were too fast to measure directly in the present experimental technique. The best fitted results of $\mathrm{MCl}$ and $\mathrm{MC} 2$ are also presented in Fig. 11, indicating that the critical cooling rates of these slags are approximately $100 \mathrm{~K} / \mathrm{s}$ and $40 \mathrm{~K} / \mathrm{s}$ for $\mathrm{MC} 1$ and $\mathrm{MC2}$, respectively.

The true reason or mechanism of the dependence of surface roughness on the cooling rate is unknown up until now. It was observed in the present work that the size of precipitated crystalline phase tended to be larger at slower cooling rate. Such observation indicates that the crystal can be allowed to be grown for longer time and the size of crystal becomes larger when the cooling rate is slower, resulting in the larger surface roughness of mold flux. Such mechanism should be confirmed or investigated in future work. Figure 11 shows the relation between the normalized cooling rate and surface roughness of industrial mold fluxes. It is recognized that these data reasonably fit the single line in Fig. 10. Thus, it is difficult to measure the critical cooling rate of slag, the critical cooling rate will be predicted from fitting of the experimental data of relation between surface roughness and cooling rate with the single line in Fig. 10. More detailed investigation should be necessary in the future to confirm the empirical relation between the surface roughness and the normalized cooling rate.

The reason why surface roughness becomes larger with smaller cooling rate is not clear. But it was observed that the size of crystal with the slower cooling rate was larger than that with the faster cooling rate. That is, the crystal grew and surface roughness became larger when it was cooled slowly. Elucidation of this mechanism is one of future research subjects.

\subsection{Evaluation of Thickness of Air Gap between the Mold Flux and Copper Mold}

It is known that air gap is often observed between the solidified mold flux and copper mold in the continuous casting machine. The role of air gap is considered as resistance of heat transfer from steel to the copper mold. According to the present experimental findings, such air gap might be formed mainly due to the precipitation of a crystalline phase. If this assumption is reasonable, the dimension of such air gap should be comparable with the surface roughness observed in the present work. There are a few available reports on the size of air gaps. Therefore, the authors tried to estimate the dimension of such air gap from the available information in the present work.

Figure 12 illustrates a schematic diagram of the temperature profile between mold and solidified shell. Assuming that the heat flux due to convection could be neglected, the total heat flux, $q$, is given by

$$
q=q_{\mathrm{c}}+q_{\mathrm{r}}
$$

where $q_{\mathrm{c}}$ and $q_{\mathrm{r}}$ are the heat fluxes due to the conduction and radiation, respectively. One dimensional heat flux to $X$ direction is assumed as shown in Fig. 12, and then $q_{\mathrm{c}}$ and $q_{\mathrm{r}}$ can be expressed as follows;

$$
q_{\mathrm{c}}=-\lambda \frac{d T}{d x}
$$




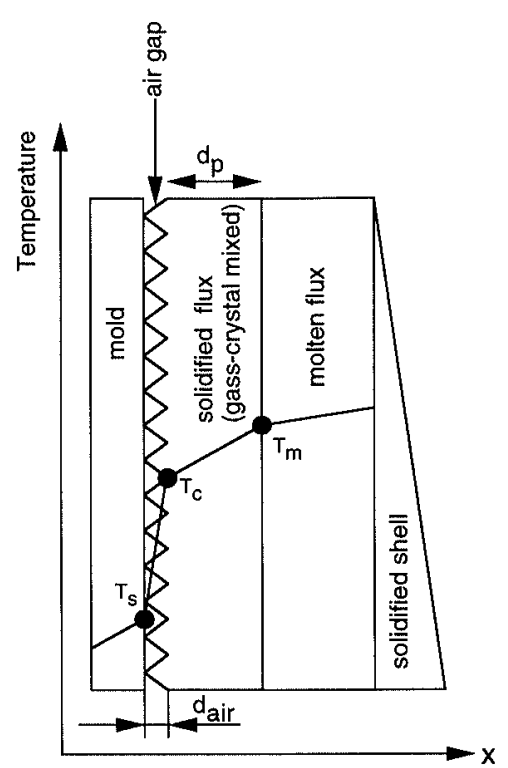

Fig. 12. Schematic diagram of temperature profile between mold and solidified shell.

$$
q_{\mathrm{r}}=\frac{n^{2} \sigma}{0.75 a d_{\mathrm{p}}+\varepsilon_{\mathrm{m}}^{-1}+\varepsilon_{\mathrm{s}}^{-1}-1}\left(T_{\mathrm{m}}^{4}-T_{\mathrm{s}}^{4}\right)
$$

where $\lambda$ is thermal conductivity, $n$ is index of refraction $a$ is absorption coefficient, $d_{\mathrm{p}}$ is thickness of mold flux film, $\varepsilon_{\mathrm{m}}$ is emissivity of mold surface, $\varepsilon_{\mathrm{s}}$ is emissivity of strand surface, and $\sigma$ is Stefan-Boltzmann constant. Although the detail mechanism has not yet been well established on the heat transfer through solidified mold flux, Watanabe et al. ${ }^{12)}$ reported that the contribution of the heat flux by radiation to total heat flux between the mold and solidified shell was estimated to be approximately $36 \%$ in the glassy layer and $13 \%$ in the crystalline layer of the mold flux for middle carbon steel casting. Since no other information is available on the heat transfer in glassy or crystalline mold flux, the average value, $25 \%$, of these contributions is employed as the heat flux by radiation in the present work. According to this assumption, the heat flux by conduction through mold flux layer is estimated as $75 \%$ of total heat flux.

$$
q_{\mathrm{c}}=0.75 q
$$

The total heat flux can be calculated as follows,

$$
q=\frac{K_{\mathrm{eff}}\left(T_{\mathrm{m}}-T_{\mathrm{c}}\right)}{d_{\mathrm{p}}}
$$

where $K_{\text {eff }}$ is effective thermal conductivity. Moreover, it is assumed that there exists air gap between the mold and surface of solidified mold flux and such air gap causes the interfacial thermal resistance.

On the other hand, it is considered that there is no accumulation of heat at the surface of solidified mold flux, and only conductive heat transfer is dominant at low temperature between solidified mold flux layer and copper mold. Thermal resistance through the mold flux layer, $R_{\mathrm{f}}$, and the interfacial resistance between solidified mold flux layer and the copper mold, $R_{\text {int }}$, by conductive heat transfer are given by as follows,
Table 3. Parameter's values for calculation of heat transfer.

\begin{tabular}{|l|r|l|}
\hline \multicolumn{1}{|c|}{ Value } & \multicolumn{1}{|c|}{ Tnvestigator } \\
\hline $\mathrm{q}$ & $1.8 \times 10^{6}\left(\mathrm{~W} / \mathrm{m}^{2}\right)$ & Hiraki et al. ${ }^{177}(\mathrm{Vc}=2 \mathrm{~m} / \mathrm{min})$ \\
\hline $\mathrm{K}_{\mathrm{air}}$ & $0.0472(\mathrm{~W} /(\mathrm{m} \cdot \mathrm{K}))$ & (Estimated value from Kagaku Binran ${ }^{19}($ at $\left.593 \mathrm{~K})\right)$ \\
\hline $\mathrm{K}_{\mathrm{ef}}$ & $1.97(\mathrm{~W} /(\mathrm{m} \cdot \mathrm{K}))$ & Watanabe et al ${ }^{12)}$ and private communication ${ }^{201}$ \\
\hline $\mathrm{T}_{\mathrm{s}}$ & $593(\mathrm{~K})$ & Koyano et al. ${ }^{18 !}$ \\
\hline $\mathrm{T}_{\mathrm{m}}$ & $1418(\mathrm{~K})$ & (MC1 in Table 1$)$ \\
\hline
\end{tabular}

$$
\begin{array}{r}
R_{\mathrm{f}}=\frac{T_{\mathrm{m}}-T_{\mathrm{c}}}{q_{\mathrm{c}}} \ldots \ldots \ldots \ldots \ldots \ldots \ldots \ldots \\
R_{\mathrm{int}}=\frac{T_{\mathrm{c}}-T_{\mathrm{s}}}{q}=\frac{T_{\mathrm{m}}-T_{\mathrm{s}}}{q}-\frac{T_{\mathrm{m}}-T_{\mathrm{c}}}{q}
\end{array}
$$

Thickness of air gap layer roughly equals to abovementioned surface roughness. The thickness of air gap concerning heat transfer is given as follows,

$$
\frac{d_{\mathrm{air}}}{2}=\frac{K_{\mathrm{air}}\left(T_{\mathrm{c}}-T_{\mathrm{s}}\right)}{q}=K_{\mathrm{air}}\left(\frac{T_{\mathrm{m}}-T_{\mathrm{s}}}{q}-\frac{T_{\mathrm{m}}-T_{\mathrm{c}}}{q}\right)
$$

Substitution of Eq. (5) in Eq. (6) gives Eq. (9).

$$
R_{\mathrm{f}}=\frac{1}{K_{\text {eff }}} \frac{q}{q_{\mathrm{c}}} d_{\mathrm{p}}
$$

Combining Eq. (5) with Eq. (7), we obtain Eq. (10).

$$
R_{\mathrm{int}}=\frac{T_{\mathrm{m}}-T_{\mathrm{s}}}{q}-\frac{1}{K_{\text {eff }}} d_{\mathrm{p}}
$$

When Eq. (5) is substituted in Eq. (8), we obtain the following equation.

$$
d_{\mathrm{air}}=2 K_{\mathrm{air}} R_{\mathrm{int}}=2 K_{\mathrm{air}}\left(\frac{\left(T_{\mathrm{m}}-T_{\mathrm{s}}\right)}{q}-\frac{1}{K_{\mathrm{eff}}} d_{\mathrm{p}}\right) .
$$

The parameter's values used for the calculation are listed in Table 3. Total heat flux, $q$, is estimated from the value at $V_{\mathrm{c}}=2 \mathrm{~m} / \mathrm{min}$ by Hiraki. ${ }^{17)}$ Since the liquidus temperature of mold flux, $T_{\mathrm{m}}$, is not known, it is assumed to be equal to the crystallization temperature of $\mathrm{MCl}$, $1418 \mathrm{~K}$ in Table 1 . The surface temperature of copper mold, $T_{\mathrm{s}}$, is $593 \mathrm{~K} .{ }^{18)}$ The effective thermal conductivity of air, $K_{\text {air }},{ }^{19)}$ is estimated at the mold surface temperature $(593 \mathrm{~K})$ under atmospheric pressure. $K_{\text {eff }}$ was estimated to be $1.97 \mathrm{~W} /(\mathrm{m} \cdot \mathrm{K})$ measured by the same experimental apparatus. ${ }^{12,20)}$ Figure 13 shows the calculated results by Eqs. (9), (10) and (11) using Eq. (4). When the thickness of the mold flux film increases, thermal resistance of the mold flux film increases, but interfacial thermal resistance decreases. It is shown in Fig. 13 that $R_{\text {int }}$ is dominant compared with $R_{\mathrm{f}}$, as mentioned earlier. The results of the interfacial thermal resistance by other reseachers ${ }^{6,12)}$ are also illustrated in Fig. 13. Both of their $R_{\text {int }}$ are in fairly good agreement with the calculated value in the present work.

Assuming thickness of mold flux film of $0.3 \mathrm{~mm}$ as suggested by Shibata, ${ }^{6}$ the thickness of air gap is estimated to be $37 \mu \mathrm{m}$ by Eq. (11). The calculated thickness of air gap, which is shown as hatched area, shows good agreement with the surface roughness of $\mathrm{MCl}$ observed in the present work as shown in Fig. 8 .

Therefore, the present authors wish to propose that the surface roughness of solidified mold flux would be 


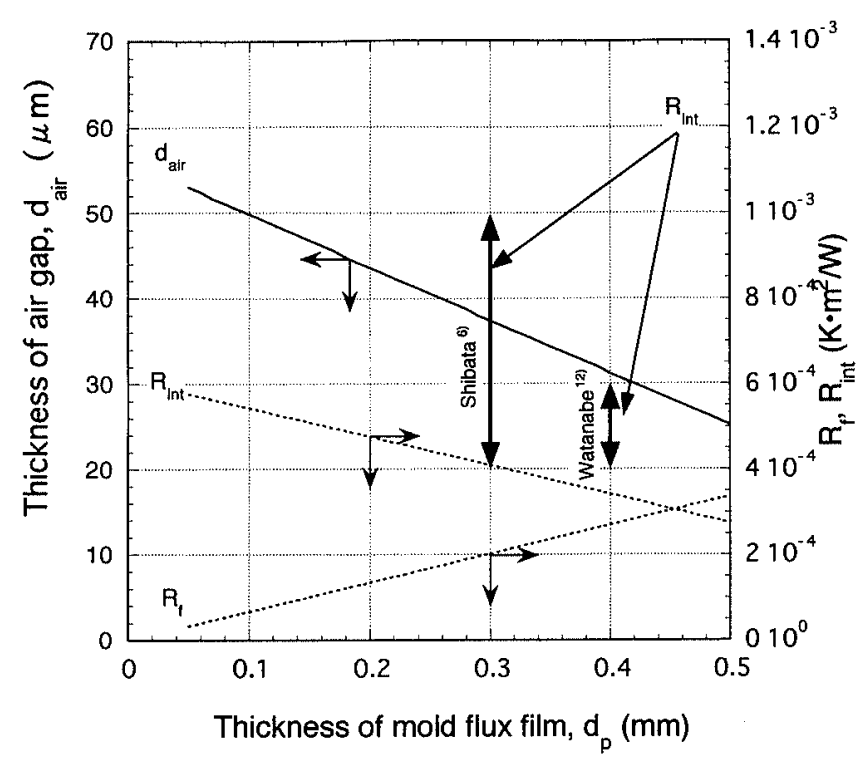

Fig. 13. Variation of thickness of air gap, $d_{\mathrm{ar}}$, and thermal resistance of mold flux, $R_{\mathrm{f}}$, and interfacial thermal resistance of mold flux, $R_{\mathrm{in}}$, with thickness of mold flux film, $d_{\mathrm{p}}$.

a reasonable index to estimate the contribution to the heat transfer from steel shell to the mold through the mold flux. That is, larger surface roughness would cause larger interfacial thermal resistance between solidified mold flux and mold. Accordingly, we must develop and select suitable mold flux which has faster critical cooling rate for the suppression of heat transfer or the achievement of a relatively slow cooling rate of steel slab.

\section{Conclusions}

The surface roughness of solidified mold fluxes and alkaline metal oxide containing mono-calcium-silicate slags has been measured by a confocal scanning laser microscope combined with an infrared image furnace. The following conclusions are obtained.

(1) The surface roughness of crystalline phase is much larger than that of glassy phase. The faster the cooling rate is, the smoother the surface roughness becomes. The surface roughness of crystalline phase is in the range of approximately $10-30 \mu \mathrm{m}$.

(2) At the constant cooling rate, the larger critical cooling rate is, the rougher surface roughness becomes, and surface roughness of mold flux for middle carbon steel casting becomes larger than that of mold flux for low carbon steel casting.

(3) The surface roughness is related to the normalized cooling rate which is defined as the ratio of real cooling rate to critical cooling rate.

(4) The calculated thickness of the air gap between the mold and the solidified mold flux was in fairly agreement with our experimental data concerning surface roughness.

\section{Acknowledgements}

The authors wish to thank Messrs. H. Yoshida (graduate students at Tohoku University) and $R$. Nakamura (undergraduate student at Tohoku Uni- versity, now Nakayama steel works, LTD. ) for their assistance and help for the experiment, and also Dr. $\mathrm{H}$. Shibata (Tohoku University) and Messrs. M. Nakada and $\mathrm{K}$. Watanabe (NKK Corp.) for useful suggestion and encouragement. Financial supports by Nippon Sheet Glass Foundation for Materials Science and Engineering are also gratefully acknowledged.

\section{Nomenclature}

$r_{\mathrm{c}}:$ cooling rate $(\mathrm{K} / \mathrm{s})$

$r_{\mathrm{cr}}:$ critical cooling rate $(\mathrm{K} / \mathrm{s})$

$r_{\mathrm{n}}$ : normalized cooling rate $(-)$

$q:$ total heat flux $\left(\mathrm{W} / \mathrm{m}^{2}\right)$

$q_{\mathrm{c}}:$ conductive heat flux $\left(\mathrm{W} / \mathrm{m}^{2}\right)$

$q_{\mathrm{r}}$ : radiative heat flux $\left(\mathrm{W} / \mathrm{m}^{2}\right)$

$\lambda: \quad$ thermal conductivity $(\mathrm{W} /(\mathrm{m} \cdot \mathrm{K}))$

$\varepsilon_{\mathrm{m}}$ : emissivity of mold surface $(-)$

$\varepsilon_{\mathrm{s}}:$ emissivity of strand surface $(-)$

$\sigma:$ Stefan-Boltzmann constant $\left(\mathrm{W} /\left(\mathrm{m}^{2} \cdot \mathrm{K}^{4}\right)\right)$

$n:$ index of refraction $(-)$

$a$ : absorption coefficient $\left(\mathrm{m}^{-1}\right)$

$d_{\mathrm{p}}$ : thickness of mold flux film (m)

$K_{\text {eff }}$ : effective thermal conductivity $(\mathrm{W} /(\mathrm{m} \cdot \mathrm{K}))$

$K_{\text {air }}$ : thermal conductivity of air $(\mathrm{W} /(\mathrm{m} \cdot \mathrm{K}))$

$T_{\mathrm{cs}}$ : crystallization temperature of mold flux (K)

$T_{\mathrm{m}}$ : liquidus temperature of mold flux (K)

$T_{\mathrm{c}}$ : surface temperature of solid mold flux in contact with copper mold $(\mathrm{K})$

$T_{\mathrm{s}}: \quad$ surface temperature of mold $(\mathrm{K})$

$d_{\text {air }}$ : thickness of air gap $(\mu \mathrm{m})$

$R_{\mathrm{f}}$ : thermal resistance through mold flux layer $\left(\mathrm{K} \cdot \mathrm{m}^{2} / \mathrm{W}\right)$

$R_{\text {int }}$ : interfacial thermal resistance between the mold flux layer and copper mold $\left(\mathrm{K} \cdot \mathrm{m}^{2} / \mathrm{W}\right)$

\section{REFERENCES}

1) Y. Sugitani, M. Nakamura and T. Wațanabe: Tetsu-to-Hagané, 67 (198I), 1508.

2) S. Ohmiya, K. H. Tacke and K. Schwerdtfeger: Ironmaking Steelmaking, 10 (1983), No. I, 24.

3) A. Yamauchi, K. Sorimachi, T. Sakuraya and T. Fujii: Tetsu-to-Hagané, 79 (1993), 167; A. Yamauchi, K. Sorimachi, T. Sakuraya and T. Fujii: ISIJ Int., 33 (1993), 140.

4) J. W. Cho, T. Emi, H. Shibata and M. Suzuki: ISIJ Int., 38 (1998), 834

5) H. Shibata, T. Emi Y. Waseda, K. Kondo, H. Ohta and K. Nakajima: Tetsu-to-Hagané, 82 (1996), 504.

6) H. Shibata, K. Kondo, M. Suzuki and T. Emi: ISIJ Int., 36 (1996), Supplement, S179.

7) S. Kumakura, H. Mizukami, T. Murakami, S. Hiraki, T. Kanazwa and T. Yamamoto: The 19th Committee, The Japan Society for the Promotion of Science, Report No. 11500, (1994).

8) T. Chikano, K. Ichikawa and O. Nomura: Shinagawa Technical Report, 31 (1988), 75.

9) M. Kawamoto, T. Tsukaguchi, N. Nishida, T. Kanazawa and S. Hiraki: ISIJ Int., 37 (1997), 134.

10) H. Nakato, M. Ozawa, K. Kinoshita, Y. Habu and T. Emi: Tetsu-to-Hagané, 67 (1981), 1200.

11) K. Kondo, H. Shibata, M. Suzuki and T. Emi: CAMP-ISIJ, 8 (1995), 165.

12) K. Watanabe, M. Suzuki, K. Murakami, H. Kondo, A. Miyamoto and T. Shomi: Tetsu-to-Hagané, 83, (1997), II 15.

13) J. W. Cho, T. Emi, H. Shibata and M. Suzuki: ISIJ Int., 38 (1998), 440.

14) K. Tsutsumi, J. Ohtake, T. Nagasaka and M. Hino: Tetsuto-Hagané, 84 (1998), 464. 
ISIJ International, Vol. 39 (1999), No. 11

15) Y.Sugitani and M. Nakamura: Tetsu-to-Hagané, 65(1979), 1702.

I6) J. W. Cho, H. Shibata T. Emi and M. Suzuki: Bull. Inst. Adv. Mater. Processing Tohoku Univ. (SOZAIKEN IHO), 53 (1997), No. $1,2,47$

17) S. Hiraki, K. Nakajima, T. Murakami and T. Kanazawa: Steelmaking Conf. Proc., ISS, Warrendale, PA, (1994), 397.
18) T. Koyano, T. Masaoka, T. Wada, T. Mori, T. Kitagawa and M. Suzuki: Tetsu-to-Hagané, 71 (1985), S1022.

19) Kagaku Binran Kisohen II, 4th ed., ed. by The Chemical Society of Japan, Maruzen, Tokyo, (1993), II-67.

20) K. Watanabe: private communication. 